\title{
Effect of the Lifting Velocity and Container Shape on Angle of Repose of Iron Ore Particles
}

\author{
Tongqing Li, ${ }^{1,2,3}$ Yuxing Peng, ${ }^{1,2,3}$ Zhencai Zhu, ${ }^{1,2,3}$ Zhangfa Yu, ${ }^{4}$ and Zixin Yin ${ }^{1,2,3}$ \\ ${ }^{1}$ School of Mechatronic Engineering, China University of Mining and Technology, Xuzhou 221116, China \\ ${ }^{2}$ Jiangsu Key Laboratory of Mine Mechanical and Electrical Equipment, China University of Mining and Technology, \\ Xuzhou 221116, China \\ ${ }^{3}$ Jiangsu Collaborative Innovation Center of Intelligent Mining Equipment, Xuzhou, China \\ ${ }^{4}$ State Key Laboratory of Mining Heavy Equipment, CITIC Heavy Industries Co., Ltd., Luoyang 471000, China
}

Correspondence should be addressed to Yuxing Peng; pengyuxingcumt@126.com

Received 25 May 2017; Revised 6 September 2017; Accepted 28 September 2017; Published 23 October 2017

Academic Editor: Alain Portavoce

Copyright (C) 2017 Tongqing Li et al. This is an open access article distributed under the Creative Commons Attribution License, which permits unrestricted use, distribution, and reproduction in any medium, provided the original work is properly cited.

To investigate the impact of lifting velocity and container shape on angle of repose, the fixed-base cylinder method was performed using three types of container shape. The container shape was lifted a series of lifting velocities. Six size fractions of iron ore particles ranging from coarser to fine particles were used as the test materials. And the sand-pile calibration method was then used to calibrate the contact parameters of iron ore particles. Results show angle of repose decreased exponentially with the lifting velocity, while it appeared approximately to be invariant to particle shape, for all size fractions. The sand pile highly depends on the container shape at a low lifting velocity but appears to be invariant to particle size for a high lifting velocity. And then a predictive equation is established and a very close agreement between the predicted and measured angle of repose is attained. Finally, a series of DEM simulations considering the irregular particle shape are conducted by means of sphere clump method to calibrate the contact parameters and are in good visual agreement with the experimental results, indicating the "tuned" contact parameters as well as the applicability of the predicted equation.

\section{Introduction}

Size reduction of minerals by grinding hitherto is a significant step in whole stage of mineral processing in which feeds are reduced in size to liberate impurities and to change the particle size distribution. The operating costs associated with size reduction are a significant discipline in mineral industry $[1,2]$. Grinding is known to be an energy-intensive operation process, since it consumes approximately two-thirds of the total energy of the mineral processing plants [3]. The literature reported that the power estimation of tumbling mills plays an important role in determining the grinding efficiency and mill performance $[4,5]$. To this end, establishing power equations of tumbling mill has attracted much attention in recent years. At present, researchers presented that mill power strongly affected by the flow properties of materials in mills [6-8]. Besides, with the rapid development of computing power and advanced contact algorithm, the Discrete Element Method (DEM) has been extensively used as a leading tool in tumbling mills. DEM simulations hitherto have been demonstrated extremely desirable to predict what happens in reality as well as the quantitatively accurate information representation inside mills, while the accuracy of outcomes for DEM simulations highly depends on the input parameters [9-14]. So far, the sand-pile calibration has been employed exclusively in determining the input parameters. The aim of this approach was to make an approximate comparison between angle of repose of experimental results and the one obtained by DEM numerical simulations. Thus, the investigation of angle of repose is of importance in studying the performance of tumbling mills.

The angle of repose is one of the most significant macroscopic parameters in characterizing the flow behavior of powders and granular materials. It is closely related to 
many phenomena, including packing $[15,16]$, avalanching $[17,18]$, and segregation and stratification [19-21], and it is therefore a research focus in recent years. The angle of repose, as a basic characteristic of granular materials in nature, has been indicated varying from $25^{\circ}$ for smooth particles to $45^{\circ}$ for irregular particles $[9,22,23]$. Currently, The literature reported that angle of repose was closely related to physical properties of granular materials such as particle shape and size [24-30] and materials properties such as shear modulus and particle moisture content and friction coefficients [12, 3133]. In the works of scholars who have studied the impact of particle shape and size on angle of repose in the literature [24-30], the angle of repose was proportional to friction coefficient and was inversely proportional to particle size. Besides, the particle shapes used were smooth, and the container shapes used were usually a cylinder. Moreover, a small lifting velocity was used to determine the impact of different factors on angle of repose [34-36]. Since it was difficult to form the sand pile in their works for high and low enough lifting velocities, however, the particle shapes used in this study were highly irregular and the particle size distribution was evidently heterogeneous. It is essential to recognize that angle of repose not only highly depends on the experimental method involved but also is strongly sensitive to container shape, due to different contact behavior [37]. To this end, the impacts of lifting velocity and container shape on angle of repose were needed.

The purpose of this study was to determine the impact of container shape and lifting velocity on the angle of repose. The test materials were iron ore samples. A series of experiments were performed on different container shapes and lifting velocities. Then the contact parameters were determined by means of the comparison of experiments and DEM simulations. Our achievements will be of great benefit for determining the flow property of iron ore particles in industrial applications.

\section{Materials and Methods}

2.1. Experimental Setup. In this study, the sand-pile test, namely, fixed-base cylinder method, was used to determine the angle of repose. This method is in accordance with the most common forming process of sand pile in nature [34]. Shown in Figure 1, the stainless steel plate used was $0.425 \mathrm{~m}$ in length and $0.45 \mathrm{~m}$ in width and was fixed horizontally on the bottom of the aluminum frame. Two fixed pulleys were installed at the top of the aluminum frame. The container was placed perpendicularly on the top of the stainless steel plate. The grooved wheel, which was coupled to a motor shaft, was used to lift the container at different lifting velocities. Finally, the iron ore particles were discharged out of the container under the natural force of gravitation forming a pile of materials and accumulated from the center of the steel plate and gradually expanded to the edge.

To study the impact of container shape on angle of repose, three kinds of containers with typical cross-sections were employed, as shown in Figure 2. The stainless steel container, opened at both ends, was $0.27 \mathrm{~m}$ in height and $0.02 \mathrm{~m}$ in thickness. The cross-sectional areas were approximately equal as well as the volume of container (Table 1).

2.2. Materials. Six different size fractions ranging from coarse particles to fine ones were used as the test materials. The iron ore samples with $67.46 \%$ grade were obtained from the Xuzhou iron mine (located in Jiangsu Province, China). The larger lumps were broken by an industrial jaw crusher followed by a laboratory-scale jaw crusher to approximately $-50 \mathrm{~mm}$. The crushed particles were then sieved carefully ( $20 \mathrm{~min}$ ) by a vibrating screen to obtain the required size fractions (Table 2). The weight of iron ore particles used in this study was $2.28 \mathrm{~kg}$.

2.3. Angle of Repose. As the container was lifted at a constant velocity, the iron ore particles spontaneously formed a sand pile. Angle of repose, as a basic parameter of particle property, defined as the angle between the inclined surface of the pile and the base surface, is known to qualitatively analyze the flow characteristic of granular particles, shown in Figure 3. For high angle, the iron ore particle starts to flow. For low angle, the iron ore particles stop flowing and become stable gradually. After sand-pile formation, the pile angles were recorded carefully with a high-precision digital protractor, and the average value was obtained and expressed as follows:

$$
\alpha_{\mathrm{AOR}}=\frac{45}{\pi}\left[\sum_{i=1}^{4} \alpha_{i}\right],
$$

where $\alpha_{i}(i=1,2,3,4)$ are the measured angle in the orthogonal axes with a unit of rad.

2.4. Procedure. Firstly, the prepared iron ore particles were poured into the container by a hopper. And then the container was lifted at different velocities, for example, $0.003 \mathrm{~m} / \mathrm{s}$, $0.007 \mathrm{~m} / \mathrm{s}, 0.01 \mathrm{~m} / \mathrm{s}, 0.03 \mathrm{~m} / \mathrm{s}, 0.07 \mathrm{~m} / \mathrm{s}, 0.1 \mathrm{~m} / \mathrm{s}, 0.3 \mathrm{~m} / \mathrm{s}$, and $0.5 \mathrm{~m} / \mathrm{s}$. Finally, the sand piles with different slope angles were formed, and therefore the corresponding angles of reposes were determined. Each test was repeated three times and the average values of repose angle were obtained.

\section{Experimental Results and Discussions}

3.1. Effect of Lifting Velocity on Angle of Repose. Figure 4 shows the angle of repose plotted against the lifting velocity for three different containers. As seen in Figure 4, it changes approximately exponentially with the lifting velocity for all size factions. For lifting velocity below $0.1 \mathrm{~m} / \mathrm{s}$, the angle of repose decreases rapidly with the increase of lifting velocity, while it decreases steadily above $0.1 \mathrm{~m} / \mathrm{s}$. The evident expanded effect of edge appears when a lifting velocity is higher enough. A high lifting velocity will cause the fierce collision in particle systems because of the high impact velocity, and there is therefore large amount of energy consumed. Thus, it is hard to form a high sand pile. For low lifting velocity, the consumed collision energy decreases. As a result, it will have high potential to form a high sand pile. Most of particles used in the literature commonly have regular 


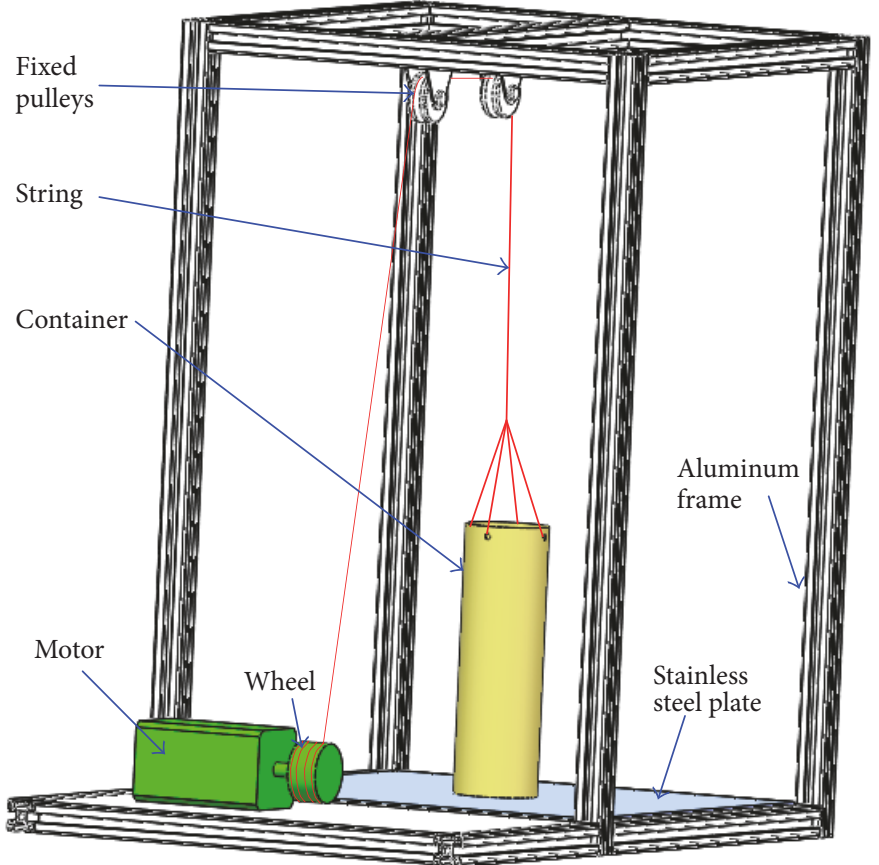

FIGURE 1: Sketch of the experimental setup used in this research.

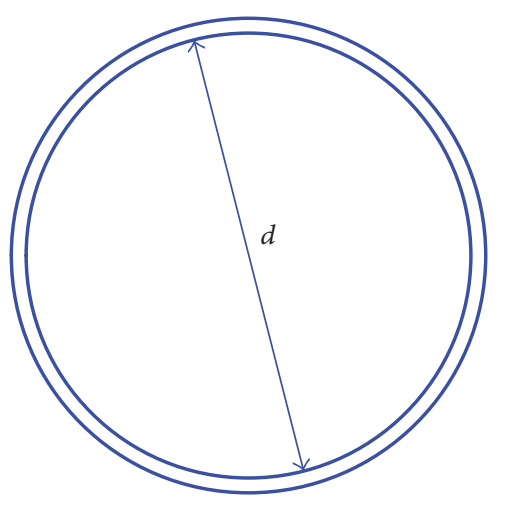

(a)

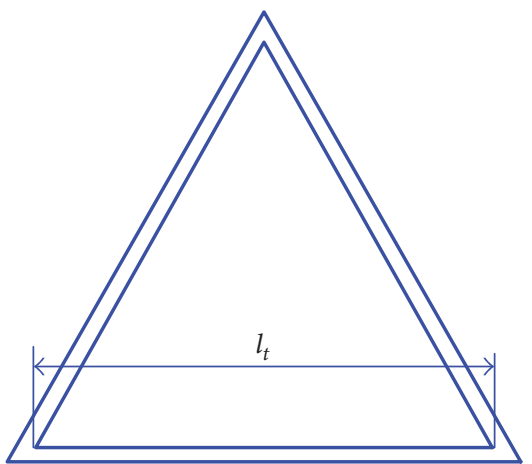

(b)

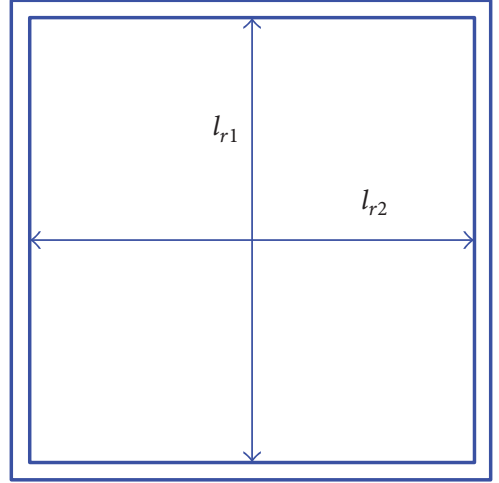

(c)

FIgURE 2: Cross-section of the container: (a) round, (b) triangle, and (c) rectangle.

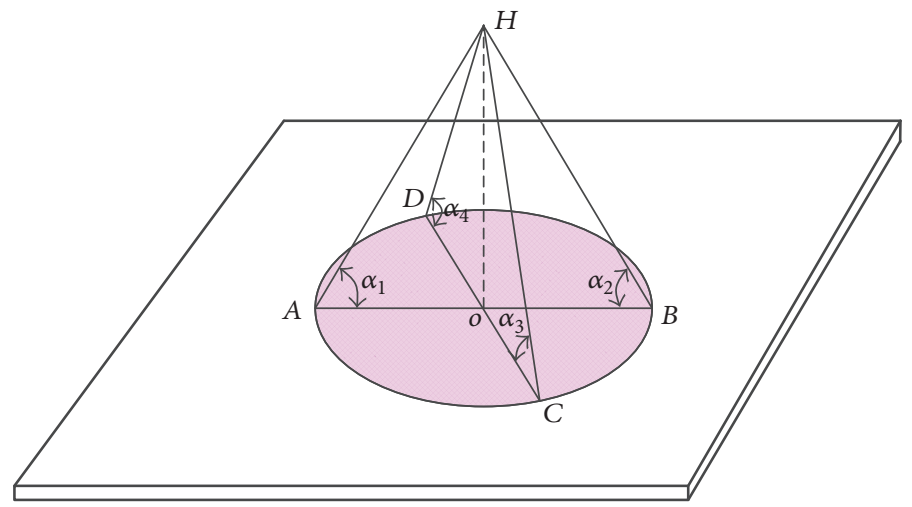

FIGURE 3: Schematic of measurement of angle of repose. 

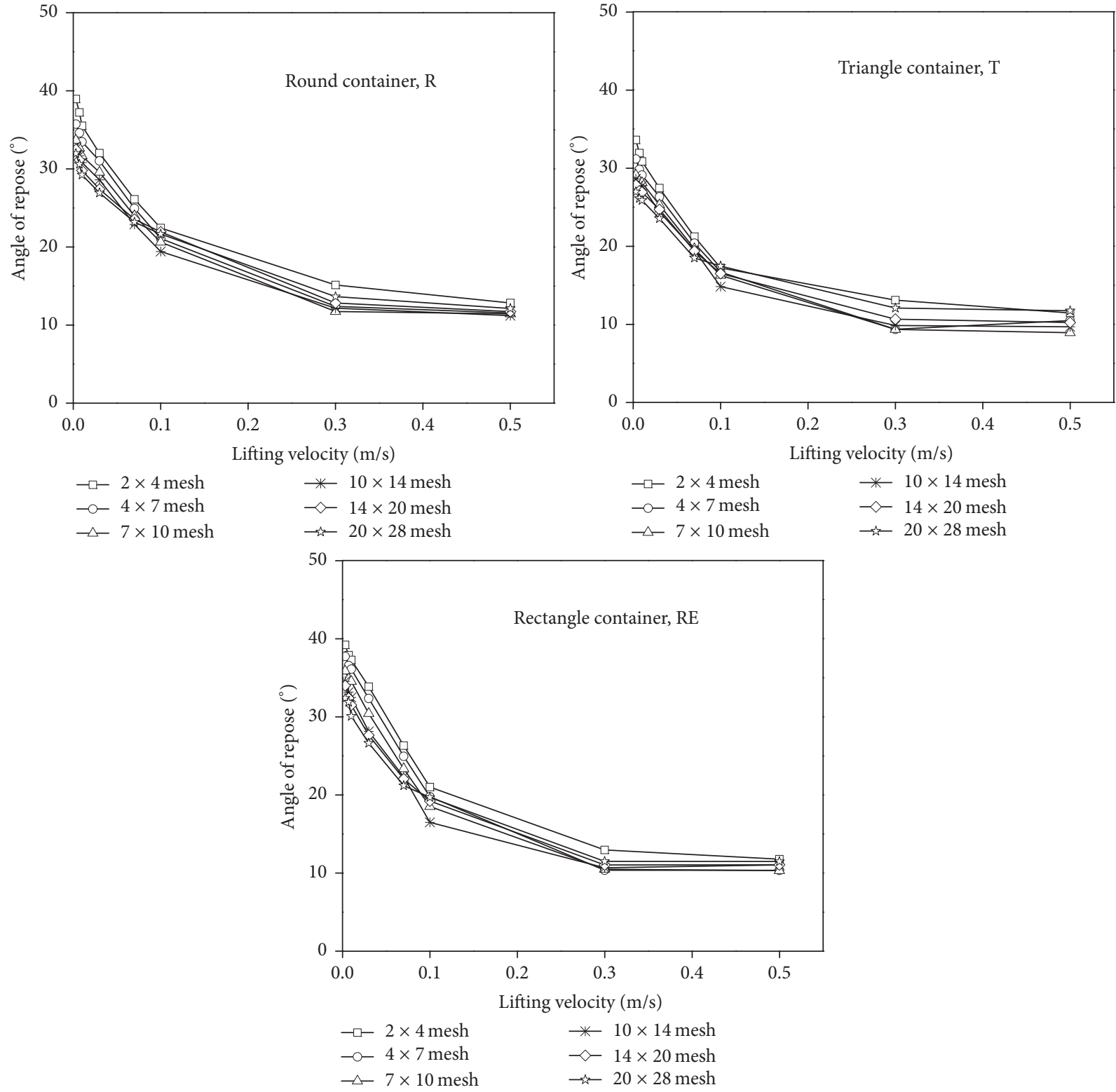

FIGURE 4: The impact of lifting velocity on angle of repose.

TABLE 1: The cross-section parameters of three containers.

\begin{tabular}{lccc}
\hline Cross section & Size $/ \mathrm{m}$ & Area $/ \mathrm{m}^{2}$ & Deviation from round shape $/ \%$ \\
\hline Round $(\mathrm{R})$ & $d=0.08$ & $5.02 e-3$ & 0 \\
Triangle (T) & $l_{t}=0.108$ & $5.03 e-3$ & 0.15 \\
Rectangle (RE) & $l_{r 1} \times l_{r 2}=0.05 \times 0.101$ & $5.05 e-3$ & 0.52 \\
\hline
\end{tabular}

TABLE 2: The size range and average size of iron ore particles.

\begin{tabular}{lcc}
\hline Size fraction & Size range/mm & Average size/mm \\
\hline $2 \times 4$ mesh & $8.5-5$ & 6.75 \\
$4 \times 7$ mesh & $5-2.3$ & 3.65 \\
$7 \times 10$ mesh & $2.3-2$ & 2.15 \\
$10 \times 14$ mesh & $2-1.4$ & 1.7 \\
$14 \times 20$ mesh & $1.4-0.9$ & 1.15 \\
$20 \times 28$ mesh & $0.9-0.63$ & 0.765 \\
\hline
\end{tabular}



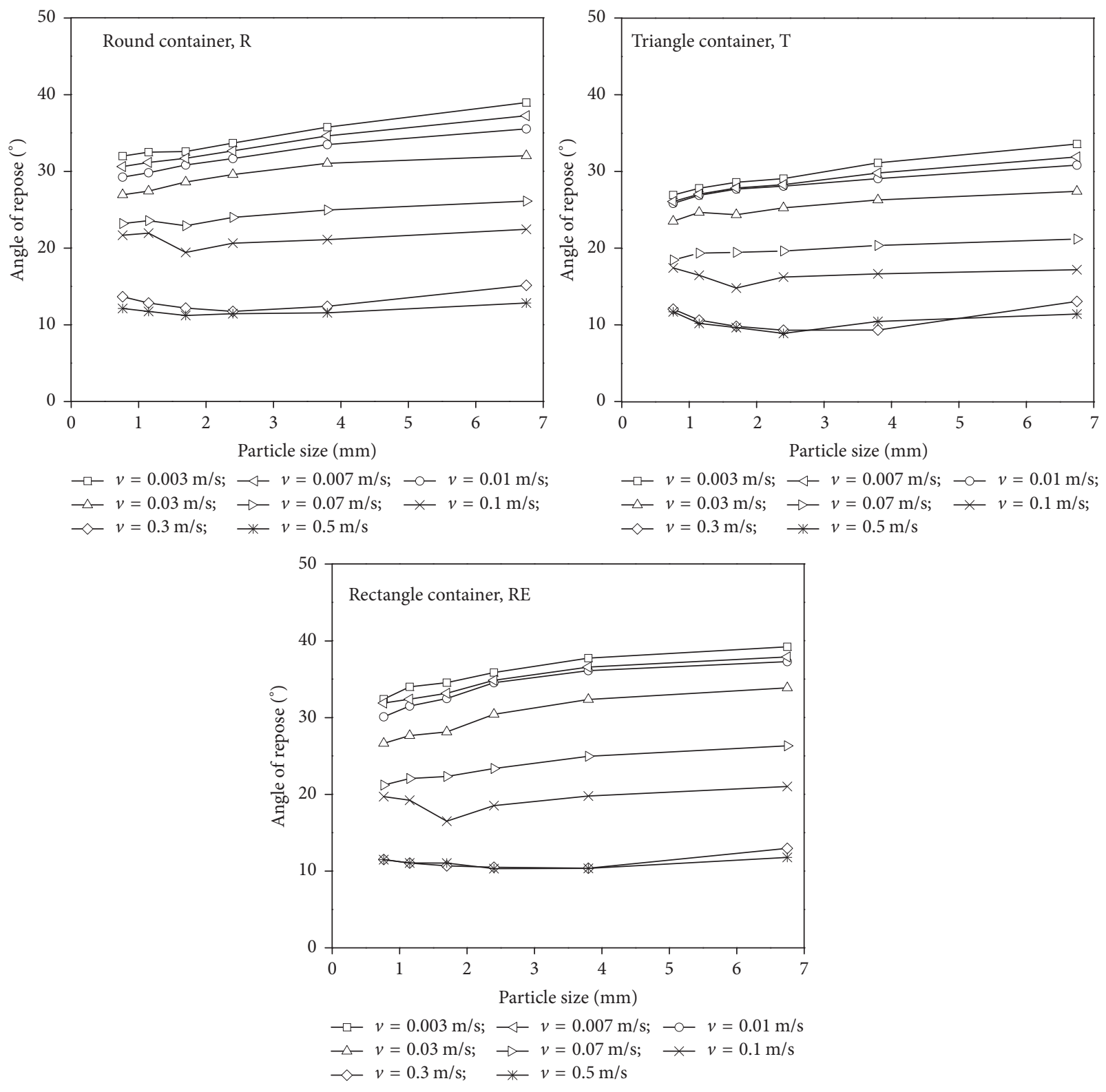

Figure 5: The impact of particle size on angle of repose.

shape and smooth surface such as glass beads and chocolate candies. It is difficult to form the sand piles at a low enough lifting velocity, due to the reduction on friction coefficient between particle-particle and particle-wall. Moreover, the iron ore particle shapes are highly irregular and the tendency of rotational motion of iron ore particles is harder than that of regular particles. Hence, the sand-pile formation of iron ore particles is markedly different from others. Additionally, it is clear that the lifting velocity has a stronger effect on angle of repose than particle size.

3.2. Effect of Particle Size on Angle of Repose. Figure 5 shows the variation of angle of repose as a function of particle size for different size fractions. The experimental errors are inevitable due to the experimental replication, and a maximum error of 1.47 and a minimum error of 0.12 are obtained. For most studies, researchers presented that increasing particle size will decrease angle of repose. As shown in Figure 5, the angle of repose slightly increases with the increase of particle size. As the lifting velocity increases, the variation on angle of repose decreases up to a minimum value and then increases slightly. For lifting velocity above $0.3 \mathrm{~m} / \mathrm{s}$, the effect of lifting velocity on angle of repose can be neglected. The effect of particle size on angle of repose is mainly due to the balance between interparticle forces and interaction forces. When particles are small, the interparticle force will play the dominant role on angle of repose, and therefore the particles will be considered as a cohesive group [22]. When the particle size is large enough, the interparticle force no longer plays a dominant role in angle of repose so 


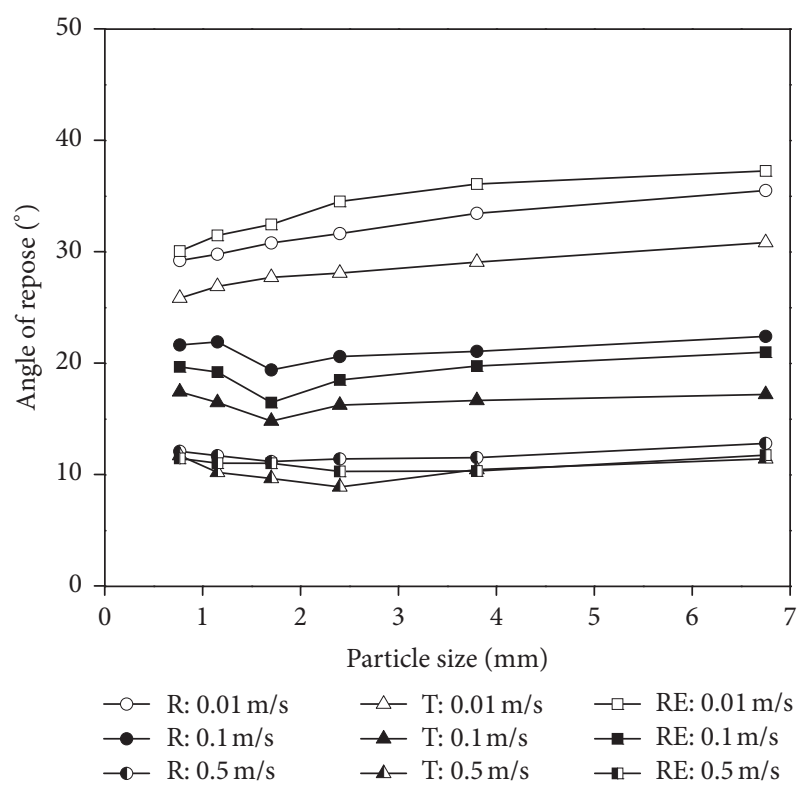

FIgURE 6: The impact of container shape on angle of repose.

that the particles behave as individual ones [22]. In addition, the shapes of coarser particles are more irregular than that of fine particles so that the friction coefficient of coarse particle is higher, resulting in high potential to form the sand pile. Moreover, the collisions of particle-particle and particle-wall are relatively gentle at a low lifting velocity, but that will be subjected to fierce collision at a high lifting velocity, resulting in more energy consumed. To sum up, it is clear that angle of repose is only a weak variation with the particle size so that the particle size effect can be neglected. Therefore it is reasonable in the practice of DEM simulation to assume a constant value of contact parameters for various particle size distributions.

3.3. Effect of Container Shape on Angle of Repose. Figure 6 shows the impact of container shape on angle of repose for three different lifting velocities, that is, a low velocity of $0.01 \mathrm{~m} / \mathrm{s}$, an intermediate velocity of $0.1 \mathrm{~m} / \mathrm{s}$, and a high velocity of $0.5 \mathrm{~m} / \mathrm{s}$. For a low lifting velocity, angle of repose formed by rectangle container (RE) is higher than that formed by round container (R). For an intermediate velocity, angle of repose formed by rectangle container (RE) is lower than that formed by round container (R). However, angles of reposes formed by rectangle container (RE) and round container (R) are obviously greater than that formed by triangle container $(\mathrm{T})$. For a high velocity, angle of repose appears approximately to be invariant to particle size. It is owing to the fact that the container shape plays significant role in the contact behavior. Broadly speaking, ball mill is fitted with various types of lifters such as lifter bar, wave lifter, and triangle lifter. Hence, the contact behaviors between the particles and lifters are markedly different, resulting in forming diverse load behavior of charge.

In this research, the coarse particles of $4 \times 7$ mesh and the fine particles of $14 \times 20$ mesh, lifted at a low velocity of
$0.01 \mathrm{~m} / \mathrm{s}$ and a high velocity of $0.1 \mathrm{~m} / \mathrm{s}$, are used to further study the boundary effect, as shown in Figure 7. From the top view, the bottom shapes of sand piles are profoundly affected by the cross-section of each container, for the lifting velocity of $0.01 \mathrm{~m} / \mathrm{s}$. However, the boundary shapes become the same for the lifting velocity of $0.1 \mathrm{~m} / \mathrm{s}$, and therefore the boundary effect disappears.

3.4. Formulation of a Predictive Equation. The above results show that the angle of repose is highly sensitive to the lifting velocity, while it appears to be invariant to particle size. The measured angle of repose is fitted using a nonlinear equation, and the equation is expressed as follows:

$$
\alpha_{\mathrm{AOR}}=k_{1}+k_{2} v \ln (v)+k_{3} d,
$$

where $k_{i}(i=1,2,3)$ are model constants, $v$ is lifting velocity, and $d$ is average particle size

Figure 8 shows the measured angle of repose plotted against the predicted values using a nonlinear model. The data listed in Figure 8 demonstrated that good agreements between measured and predicted angle of repose indicate the applicability of this equation in this work. This equation can enormously shorten the measurement time of angle of repose and improve the efficiency for studying the input parameters of DEM simulations.

\section{DEM Simulations}

To determine the DEM input parameters, the sand-pile calibration method is used to make an approximate comparison between angle of repose of experimental results and the one obtained by DEM numerical simulations. A series of DEM simulations are conducted on the samples of $4 \times 7$ mesh due to the weak sensitivity to particle size. Considering the rationality of lifting velocity, the round container is lifted at a constant velocity of $0.01 \mathrm{~m} / \mathrm{s}$. In this study, twenty-eight particles were used to generate the 3D digitized and meshed shapes by a high-accuracy 3D scanner (TEXU-BLU, 2M pixels). Sphericity can define the shape of the particle to a very good extent with a simple method and has been used extensively in powder technology [38].

$$
\Psi=\frac{\mathrm{SA}_{\mathrm{es}}}{\mathrm{SA}_{\mathrm{rp}}}=\frac{\sqrt[3]{36 \pi V^{2}}}{\mathrm{SA}_{\mathrm{rp}}},
$$

where $\mathrm{SA}_{\mathrm{rp}}$ is the real surface area of the iron ore particle, $\mathrm{SA}_{\mathrm{es}}$ is the surface area of sphere determined by the same volume of iron ore particle, and $V$ is the real volume of iron ore particle. The real physical properties of twenty-eight particles are calculated as shown in Table 3.

The geometrical dimensions of iron ore particles are determined on the basis of the 3D digitized and meshed shapes. Considering the equivalent sphere with the same volume of the real particle, the equivalent surface areas are calculated in Table 3, as shown in Figure 9. The equivalent surface area versus the real surface area is fitted by the method of least squares. The fitting value has a sphericity of 0.758 and a correlation coefficient of 0.95 which are slightly smaller than 

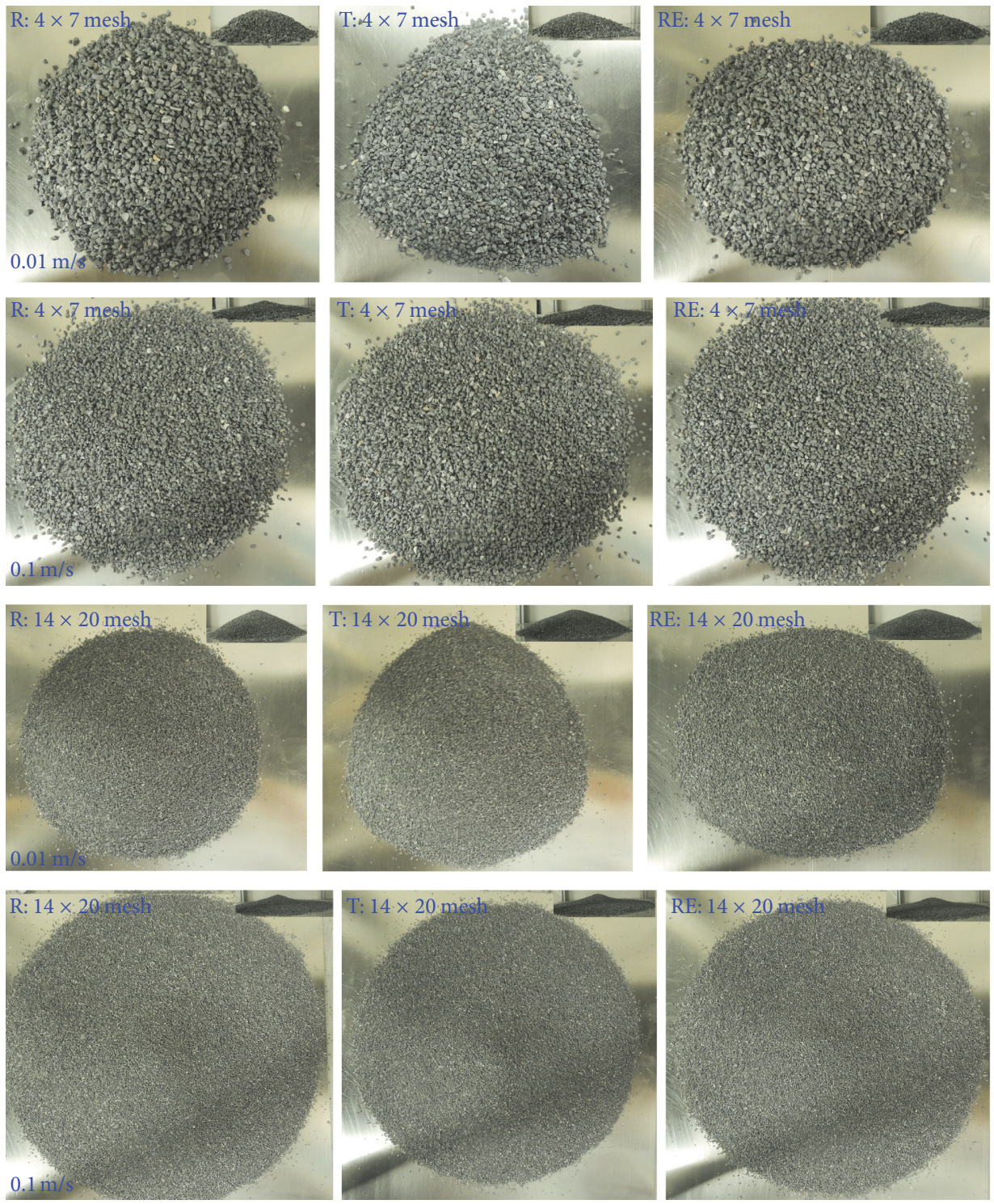

Figure 7: The sand-piles formation $(4 \times 7$ mesh and $14 \times 20 \mathrm{mesh})$ at the velocity of $0.01 \mathrm{~m} / \mathrm{s}$ and $0.1 \mathrm{~m} / \mathrm{s}$.

is the case for the average value (0.782), but both are less than the sphericity of sphere. It is demonstrated that the iron ore particle is highly irregular comparing with the sphere so that the simplifications and assumptions of irregular particle as simple spherical shape are unrealistic.

Hence, to allow the irregular shape to be accurately determined, the sphere clump method is employed in modelling the particle shape. An example of a modelled iron ore particle is shown in Figure 10. The no-slip Hertz-Mindlin model is employed to figure out the contact force between particle systems within the EDEM software package (DEM-Solutions Ltd., Edinburgh, UK). To achieve computational accuracy without increasing the amount of calculation, the geometrical model used in the work is a cluster of thirty overlapping spheres. In EDEM software any kind of irregular geometrical shape of particles can be generated as a clump composed of several touching or overlapping spheres. Therefore, the contact detection between the sphere clumps is spherebased and, therefore, the discrete element algorithm of the sphere clumps is fully available for calculating the contact forces.

The mechanical properties of iron ores and walls are conducted using hydraulic MTS machine. The contact parameters between particle and wall are determined by means of drop test and pin-on-disk tribometer tester. The interparticle contact parameters are determined previously by authors. It is useful to determine which contact parameter has the greatest impact on angle of repose. A series of DEM simulations present that friction coefficient has the primary impact on angle of repose rather than restitution coefficient. Then adjustments could be made to the friction coefficient until DEM simulations match the experimental results. The simulated test shows a good visual agreement with the experimental results, shown in Figure 11. 

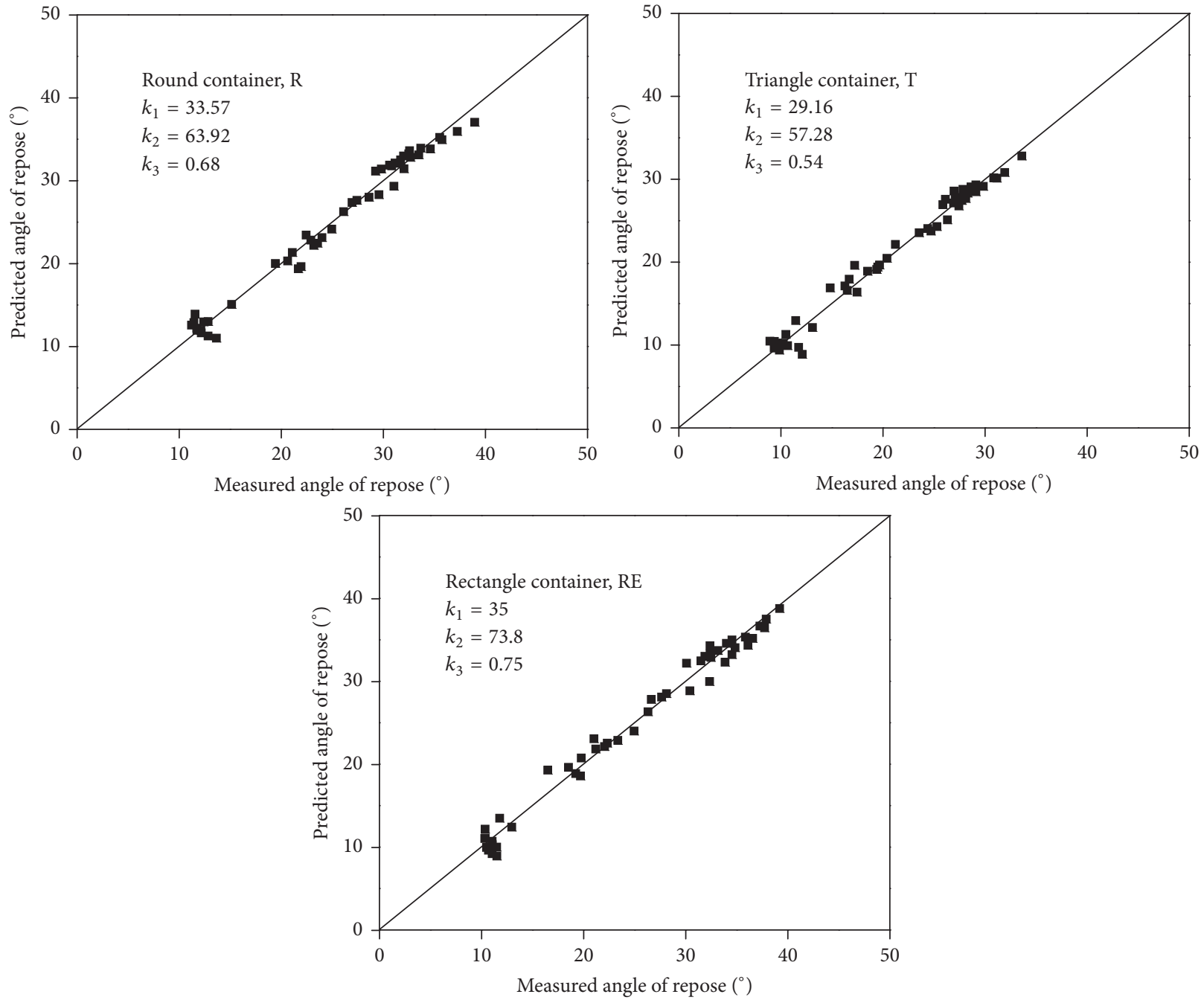

FIGURE 8: Effect of measured angle of repose with predicted angle of repose.

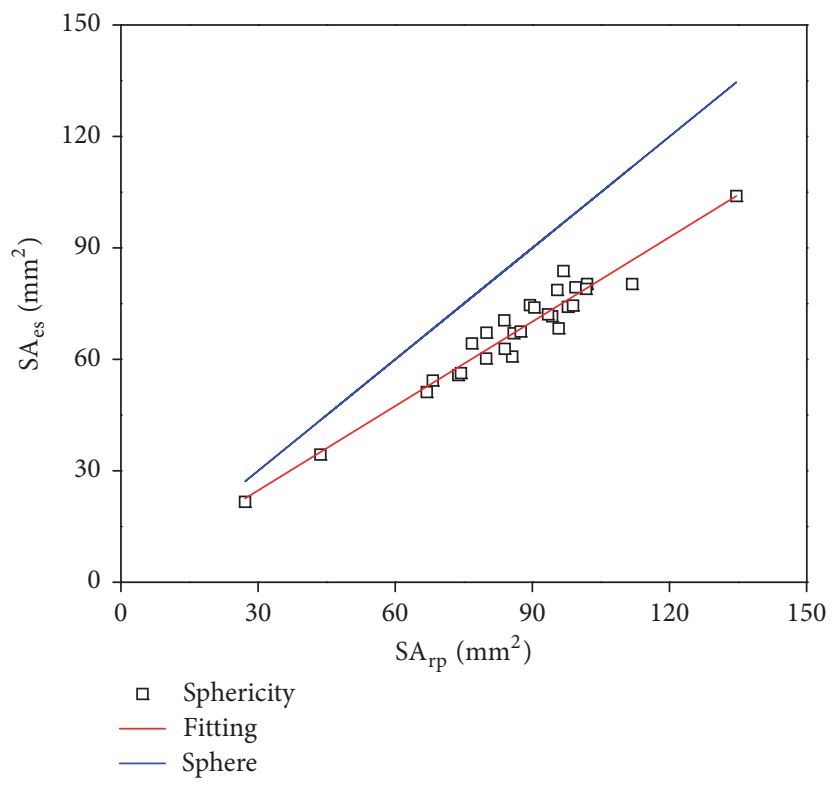

FIGURE 9: Sphericity of twenty-eight iron ore particles. 
TABLE 3: The real physical properties of twenty-eight particles.

\begin{tabular}{|c|c|c|c|c|c|c|c|}
\hline Number & $x(\mathrm{~mm})$ & $y(\mathrm{~mm})$ & $z(\mathrm{~mm})$ & $\mathrm{SA}_{\mathrm{rp}}\left(\mathrm{mm}^{2}\right)$ & $V\left(\mathrm{~mm}^{3}\right)$ & $\mathrm{SA}_{\mathrm{es}}\left(\mathrm{mm}^{2}\right)$ & $\Psi$ \\
\hline (1) & 6.92 & 4.153 & 5.72 & 85.57 & 44.51 & 60.73 & 0.71 \\
\hline (2) & 5.70 & 6.195 & 6.73 & 101.94 & 67.65 & 80.29 & 0.79 \\
\hline (3) & 9.22 & 5.418 & 5.03 & 111.81 & 67.63 & 80.27 & 0.72 \\
\hline (4) & 7.30 & 4.968 & 5.31 & 101.71 & 65.98 & 78.96 & 0.78 \\
\hline (5) & 7.28 & 6.536 & 3.29 & 95.74 & 53.11 & 68.33 & 0.71 \\
\hline (6) & 6.79 & 3.943 & 6.52 & 97.75 & 60.00 & 74.11 & 0.76 \\
\hline (7) & 7.13 & 6.117 & 5.23 & 98.88 & 60.43 & 74.47 & 0.75 \\
\hline (8) & 9.97 & 5.003 & 5.20 & 134.60 & 99.67 & 103.96 & 0.77 \\
\hline (9) & 8.35 & 4.081 & 5.34 & 99.41 & 66.52 & 79.39 & 0.80 \\
\hline (10) & 6.70 & 5.187 & 5.12 & 94.30 & 56.94 & 71.58 & 0.76 \\
\hline (11) & 6.85 & 3.749 & 4.91 & 73.78 & 39.14 & 55.75 & 0.76 \\
\hline (12) & 7.45 & 5.429 & 4.62 & 83.94 & 46.83 & 62.83 & 0.75 \\
\hline (13) & 7.29 & 5.093 & 4.57 & 89.45 & 60.56 & 74.58 & 0.83 \\
\hline (14) & 6.06 & 3.952 & 5.04 & 74.37 & 39.72 & 56.30 & 0.76 \\
\hline (15) & 6.45 & 5.054 & 5.07 & 83.84 & 55.64 & 70.48 & 0.84 \\
\hline (16) & 5.92 & 5.930 & 5.92 & 90.42 & 59.78 & 73.94 & 0.82 \\
\hline (17) & 6.88 & 4.899 & 4.27 & 79.88 & 43.93 & 60.21 & 0.75 \\
\hline (18) & 3.81 & 3.02 & 2.87 & 27.14 & 9.46 & 21.64 & 0.80 \\
\hline (19) & 5.65 & 4.32 & 5.47 & 76.76 & 48.43 & 64.25 & 0.84 \\
\hline (20) & 2.52 & 6.20 & 5.11 & 66.89 & 34.43 & 51.18 & 0.77 \\
\hline (21) & 3.87 & 5.41 & 5.36 & 68.21 & 37.60 & 54.28 & 0.80 \\
\hline (22) & 4.22 & 5.60 & 7.26 & 93.42 & 57.57 & 72.10 & 0.77 \\
\hline (23) & 3.96 & 4.25 & 3.69 & 43.62 & 18.94 & 34.36 & 0.79 \\
\hline (24) & 6.32 & 5.53 & 4.38 & 79.94 & 51.78 & 67.18 & 0.84 \\
\hline (25) & 6.30 & 5.66 & 4.89 & 96.79 & 72.10 & 83.77 & 0.87 \\
\hline (26) & 4.92 & 4.98 & 8.02 & 85.89 & 51.58 & 67.01 & 0.78 \\
\hline (27) & 4.85 & 5.90 & 6.24 & 87.44 & 52.12 & 67.47 & 0.77 \\
\hline (28) & 5.86 & 6.14 & 5.28 & 95.43 & 65.60 & 78.66 & 0.82 \\
\hline
\end{tabular}

Using the appropriate parameters used in the slump tests, a series of DEM simulations on angle of repose are conducted. Figure 11 compares the experimental and simulated slump test on iron ore particles. It indicates that the DEM simulations using the sphere clump methods are in good visual agreement with the experimental results, implying the "tuned" contact parameters. In order to test the obtained contact parameters, the comparisons between DEM simulations and experimental results are studied at the lifting velocity of $0.01 \mathrm{~m} / \mathrm{s}$ and $0.1 \mathrm{~m} / \mathrm{s}$, using three containers, as shown in Figure 12.

Figure 12 shows the relationship among measured and calculated and DEM simulation results. As seen in Figure 12, the DEM simulations considering the irregular shape are in good visual agreement with the experimental results as well as the calculated results. The standard deviation is approximately 1.6 degrees, which almost within the measurement error.

\section{Conclusions}

The results presented above contribute to a better understanding of the impact of lifting velocity and particle size on angle of repose of iron ore particles. Three types of container shape were used to conduct the experiments on six size fractions ranging from coarser particles to fine ones. And the sand-pile calibration method was then used to calibrate the contact parameters. Results have shown that angle of repose decreased exponentially with the lifting velocity, while it appeared approximately to be invariant to particle shape. Hence, the impact of lifting velocity was more profound than that of particle size. For a low lifting velocity, the sand piles highly depended on the container shape. For a high lifting velocity, it appeared to be invariant to the particle size. Subsequently, a predictive equation is established to quantitatively study the impact of lifting velocity and particle size on angle of repose of iron ore particles. Finally, a sphere clump method was used to generate the geometrical model of real particles using a cluster of thirty overlapping spheres. Based on the sand-pile and DEM simulations, a very close agreement between the predicted and measured angle of repose is attained. The contact parameters determined by DEM simulations show a good approximation to the experimental and calculated results, indicating the "tuned" contact parameters as well as the applicability of the predicted equation. 

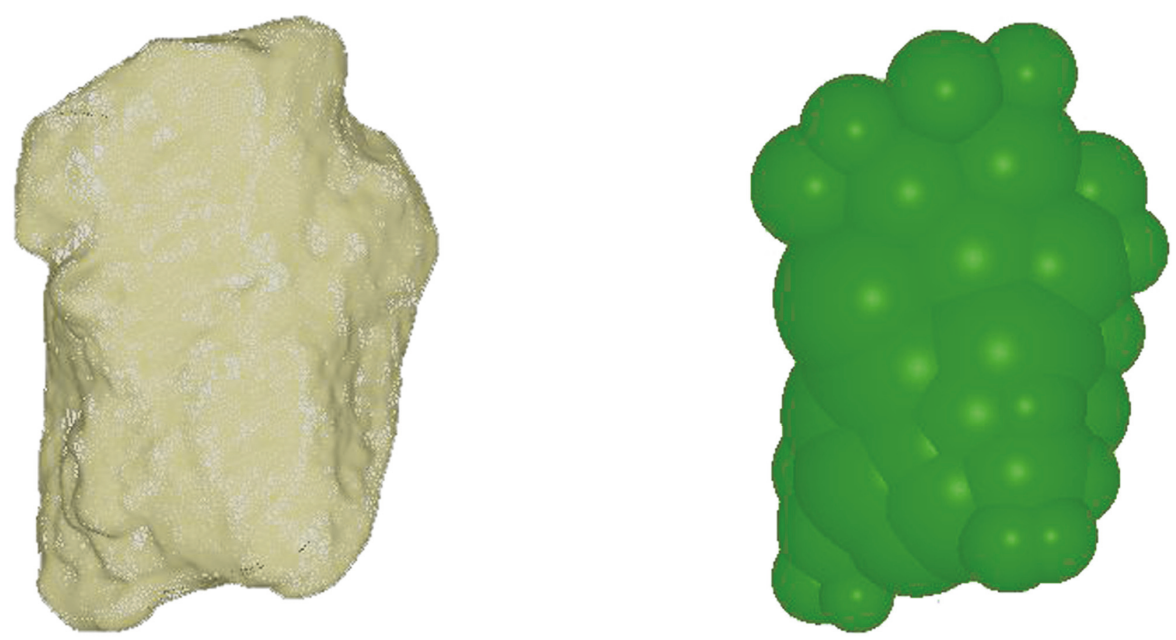

FIGURE 10: Iron ore particle modelling by the sphere clump method (thirty spheres).

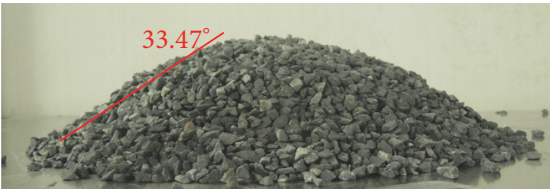

(a)

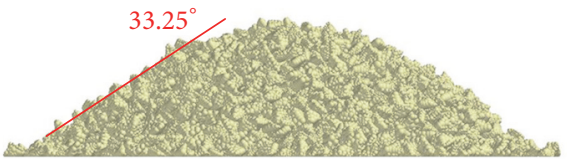

(b)

FIgURE 11: Experimental (a) and simulated (b) test on iron ore particles.

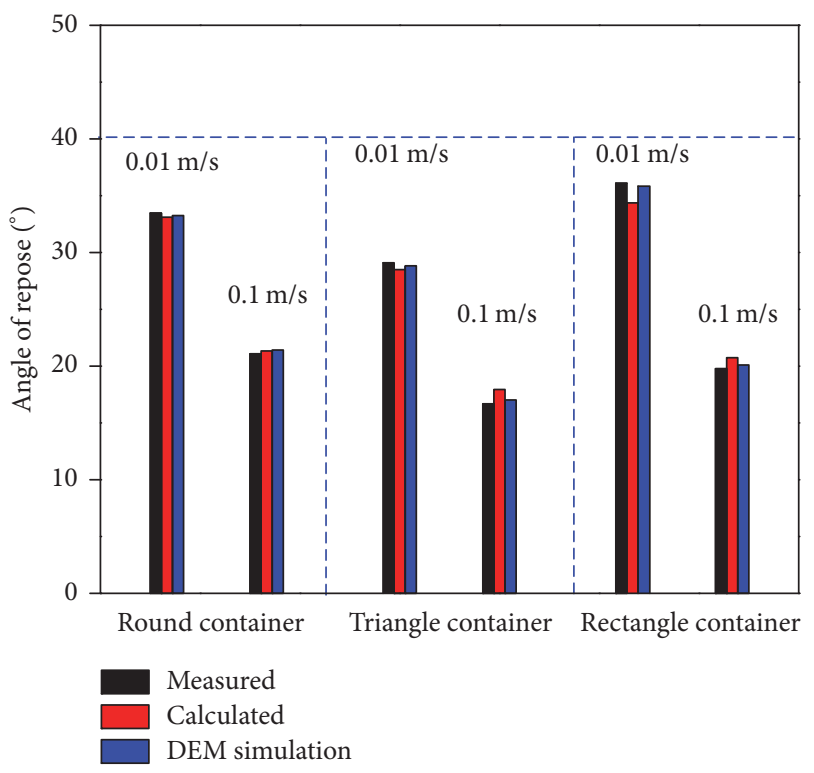

FIGURE 12: Comparison of measured, calculated, and DEM simulation on angle of repose.

\section{Conflicts of Interest}

The authors declare no conflicts of interest.

\section{Authors' Contributions}

Yuxing Peng proposed the research topic; Zhangfa Yu contributed materials to the work; Zhencai Zhu guided and supervised the entire project; Tongqing $\mathrm{Li}$ wrote the manuscript and analyzed the data; Yuxing Peng and Zixin Yin made the revisions of the manuscript.

\section{Acknowledgments}

The research reported here was supported by the National Nature Science Foundation of China (Grant no. 51475458), Key Project of National Natural Science Foundation of China (Grant no. U1510205), and the Program for Changjiang Scholars and Innovative Research Team in University (IRT_16R68). The authors also wish to thank the Priority Academic Program Development of Jiangsu Higher Education Institutions (PAPD) and the Top-Notch Academic Programs Project of Jiangsu Higher Education Institutions (TATP).

\section{References}

[1] K. Zhang, A. Nieto, and A. N. Kleit, "The real option value of mining operations using mean-reverting commodity prices," Mineral Economics, vol. 28, no. 1-2, pp. 11-22, 2015.

[2] K. Zhang and A. N. Kleit, "Mining rate optimization considering the stockpiling: A theoretical economics and real option model," Resources Policy, vol. 47, pp. 87-94, 2016. 
[3] L. G. Austin, R. R. Klimpel, and P. T. Luckie, "Process Engineering of Size Reduction: Ball Milling," in Institute of Mining, Metallurgical, and Petroleum Engineers, pp. 1-38, American Institute of Mining, New Jersey, NJ, USA, 1984.

[4] F. S. Hoseinian, R. S. Faradonbeh, A. Abdollahzadeh, B. Rezai, and S. Soltani-Mohammadi, "Semi-autogenous mill power model development using gene expression programming," Powder Technology, vol. 308, pp. 61-69, 2017.

[5] R. E. McIvor, "Correspondence to mill power draw paper," Minerals Engineering, vol. 108, pp. 31-35, 2017.

[6] L. S. Bbosa, I. Govender, and A. Mainza, "Development of a novel methodology to determine mill power draw," International Journal of Mineral Processing, vol. 149, pp. 94-103, 2016.

[7] I. Govender, "Granular flows in rotating drums: A rheological perspective," Minerals Engineering, vol. 92, pp. 168-175, 2016.

[8] I. Govender and M. S. Powell, "An empirical power model derived from 3D particle tracking experiments," Minerals Engineering, vol. 19, no. 10, pp. 1005-1012, 2006.

[9] Y. C. Zhou, B. H. Xu, A. B. Yu, and P. Zulli, "An experimental and numerical study of the angle of repose of coarse spheres," Powder Technology, vol. 125, no. 1, pp. 45-54, 2002.

[10] A. P. Grima and P. W. Wypych, "Investigation into calibration of discrete element model parameters for scale-up and validation of particle-structure interactions under impact conditions," Powder Technology, vol. 212, no. 1, pp. 198-209, 2011.

[11] T.-T. Ng, "Input parameters of discrete element methods," Journal of Engineering Mechanics, vol. 132, no. 7, pp. 723-729, 2006.

[12] Z. Yan, S. K. Wilkinson, E. H. Stitt, and M. Marigo, "Discrete element modelling (DEM) input parameters: understanding their impact on model predictions using statistical analysis," Computational Particle Mechanics, vol. 2, no. 3, pp. 283-299, 2015.

[13] S. K. Wilkinson, S. A. Turnbull, Z. Yan, E. H. Stitt, and M. Marigo, "A parametric evaluation of powder flowability using a Freeman rheometer through statistical and sensitivity analysis: A discrete element method (DEM) study," Computers \& Chemical Engineering, vol. 97, pp. 161-174, 2017.

[14] C. J. Coetzee, "Calibration of the discrete element method and the effect of particle shape," Powder Technology, vol. 297, pp. 5070, 2016.

[15] C. Li, T. Honeyands, D. O'Dea, and R. Moreno-Atanasio, “The angle of repose and size segregation of iron ore granules: DEM analysis and experimental investigation," Powder Technology, vol. 320, pp. 257-272, 2017.

[16] B.-B. Dai, J. Yang, and C.-Y. Zhou, "Micromechanical origin of angle of repose in granular materials," Granular Matter, vol. 19, no. 2, article 24, 2017.

[17] N. Cheng and K. Zhao, "Difference between static and dynamic angle of repose of uniform sediment grains," International Journal of Sediment Research, vol. 32, pp. 149-154, 2016.

[18] H. Yang, B. F. Zhang, R. Li, G. Zheng, and V. Zivkovic, "Particle dynamics in avalanche flow of irregular sand particles in the slumping regime of a rotating drum," Powder Technology, vol. 311, pp. 439-448, 2017.

[19] C. C. Liao, S. S. Hsiau, and S. F. Wen, "Effect of adding a small amount of liquid on density-induced wet granular segregation in a rotating drum," Advanced Powder Technology, vol. 27, no. 4, pp. 1265-1271, 2016.

[20] H. Xiao, D. McDonald, Y. Fan, P. B. Umbanhowar, J. M. Ottino, and R. M. Lueptow, "Controlling granular segregation using modulated flow," Powder Technology, vol. 312, pp. 360-368, 2017.
[21] J. Baxterl, U. Tüzün, D. Heyes et al., "Stratification in poured granular heaps," Nature, vol. 391, p. 136, 1998.

[22] W. Wang, J. Zhang, S. Yang, H. Zhang, H. Yang, and G. Yue, "Experimental study on the angle of repose of pulverized coal," Particuology, vol. 8, no. 5, pp. 482-486, 2010.

[23] K. E. Ileleji and B. Zhou, "The angle of repose of bulk corn stover particles," Powder Technology, vol. 187, no. 2, pp. 110-118, 2008.

[24] Z. Guo, X. Chen, H. Liu, Q. Guo, X. Guo, and H. Lu, "Theoretical and experimental investigation on angle of repose of biomasscoal blends," Fuel, vol. 116, pp. 131-139, 2014.

[25] P. Vangla and M. L. Gali, "Effect of particle size of sand and surface asperities of reinforcement on their interface shear behaviour," Geotextiles and Geomembranes, vol. 44, no. 3, pp. 254-268, 2016.

[26] K. Dong, C. Wang, and A. Yu, "A novel method based on orientation discretization for discrete element modeling of nonspherical particles," Chemical Engineering Science, vol. 126, pp. 500-516, 2015.

[27] Z. Y. Zhou, R. P. Zou, D. Pinson, and A. B. Yu, "Angle of repose and stress distribution of sandpiles formed with ellipsoidal particles," Granular Matter, vol. 16, no. 5, pp. 695-709, 2014.

[28] J.-F. Ferellec and G. R. McDowell, "A method to model realistic particle shape and inertia in DEM," Granular Matter, vol. 12, no. 5, pp. 459-467, 2010.

[29] D. Li, G. Liu, H. Lu, Q. Zhang, Q. Wang, and H. Yu, "Numerical simulation of different flow regimes in a horizontal rotating ellipsoidal drum," Powder Technology, vol. 291, pp. 86-96, 2016.

[30] D. Li, L. Wang, Q. Wang et al., "Simulations of dynamic properties of particles in horizontal rotating ellipsoidal drums," Applied Mathematical Modelling: Simulation and Computation for Engineering and Environmental Systems, vol. 40, no. 17-18, pp. 7708-7723, 2016.

[31] G. K. P. Barrios, R. M. de Carvalho, A. Kwade, and L. M. Tavares, "Contact parameter estimation for DEM simulation of iron ore pellet handling," Powder Technology, vol. 248, pp. 84-93, 2013.

[32] A. P. Grima and P. W. Wypych, "Development and validation of calibration methods for discrete element modelling," Granular Matter, vol. 13, no. 2, pp. 127-132, 2011.

[33] M. Combarros, H. J. Feise, H. Zetzener, and A. Kwade, "Segregation of particulate solids: Experiments and DEM simulations," Particuology, vol. 12, no. 1, pp. 25-32, 2014.

[34] J. Liu, B. Yun, and C. Zhao, "Identification and validation of rolling friction models by dynamic simulation of sandpile formation," International Journal of Geomechanics, vol. 12, no. 4, pp. 484-493, 2012.

[35] H. Chen, Y. L. Liu, X. Q. Zhao, Y. G. Xiao, and Y. Liu, "Numerical investigation on angle of repose and force network from granular pile in variable gravitational environments," Powder Technology, vol. 283, no. 7-8, pp. 607-617, 2015.

[36] Y. C. Zhou, B. D. Wright, R. Y. Yang et al., "Rolling friction in the dynamic simulation of sandpile formation," Physica A Statistical Mechanics \& Its Application, vol. 269, no. 2-4, pp. 536-553, 1999.

[37] M. Y. Matsuo, D. Nishiura, and H. Sakaguchi, "Geometric effect of angle of repose revisited," Granular Matter, vol. 16, no. 4, pp. 441-447, 2014.

[38] B. Majidi, K. Azari, H. Alamdari, M. Fafard, and D. Ziegler, "Simulation of vibrated bulk density of anode-grade coke particles using discrete element method," Powder Technology, vol. 261, no. 7, pp. 154-160, 2014. 

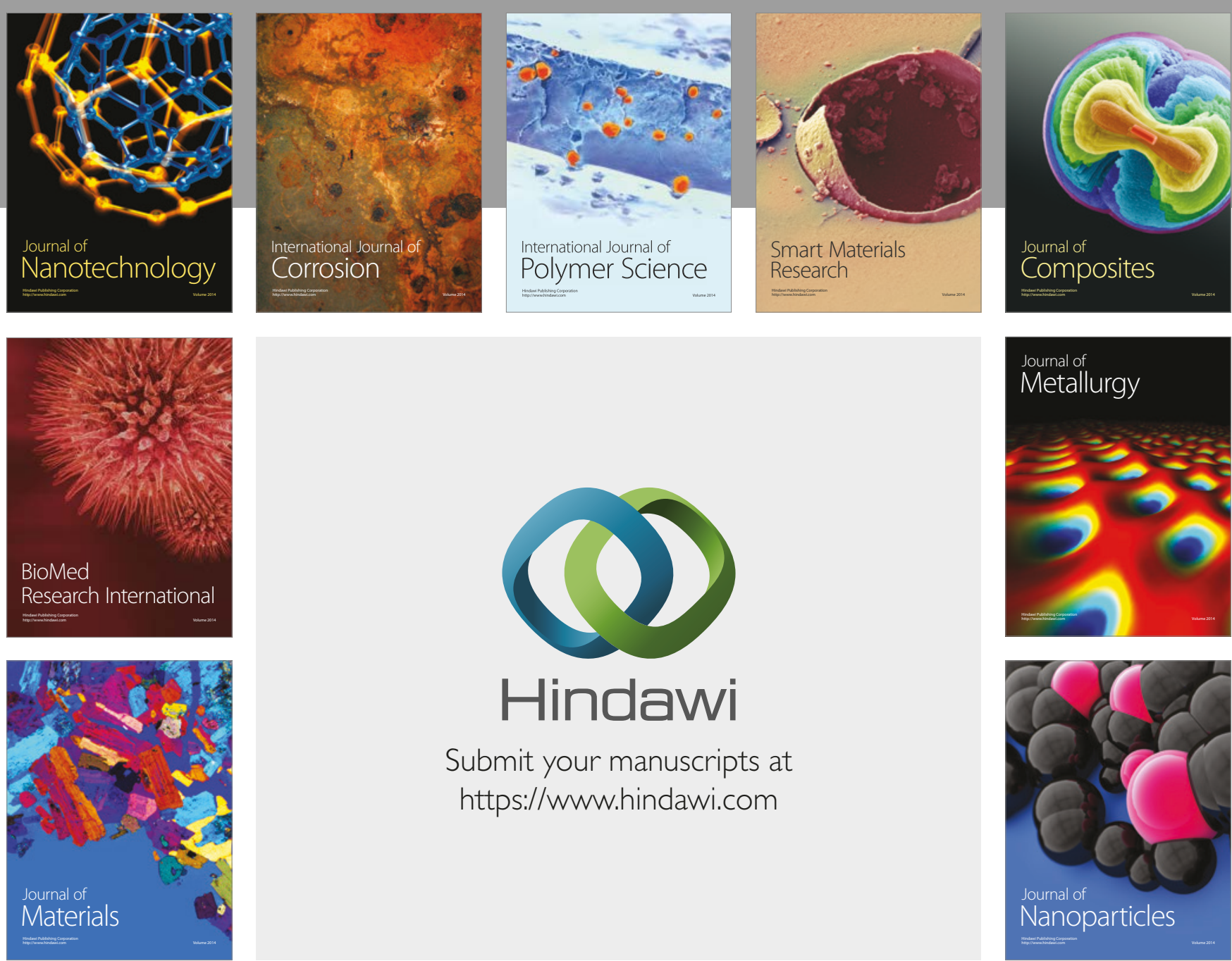

\section{Hindawi}

Submit your manuscripts at

https://www.hindawi.com
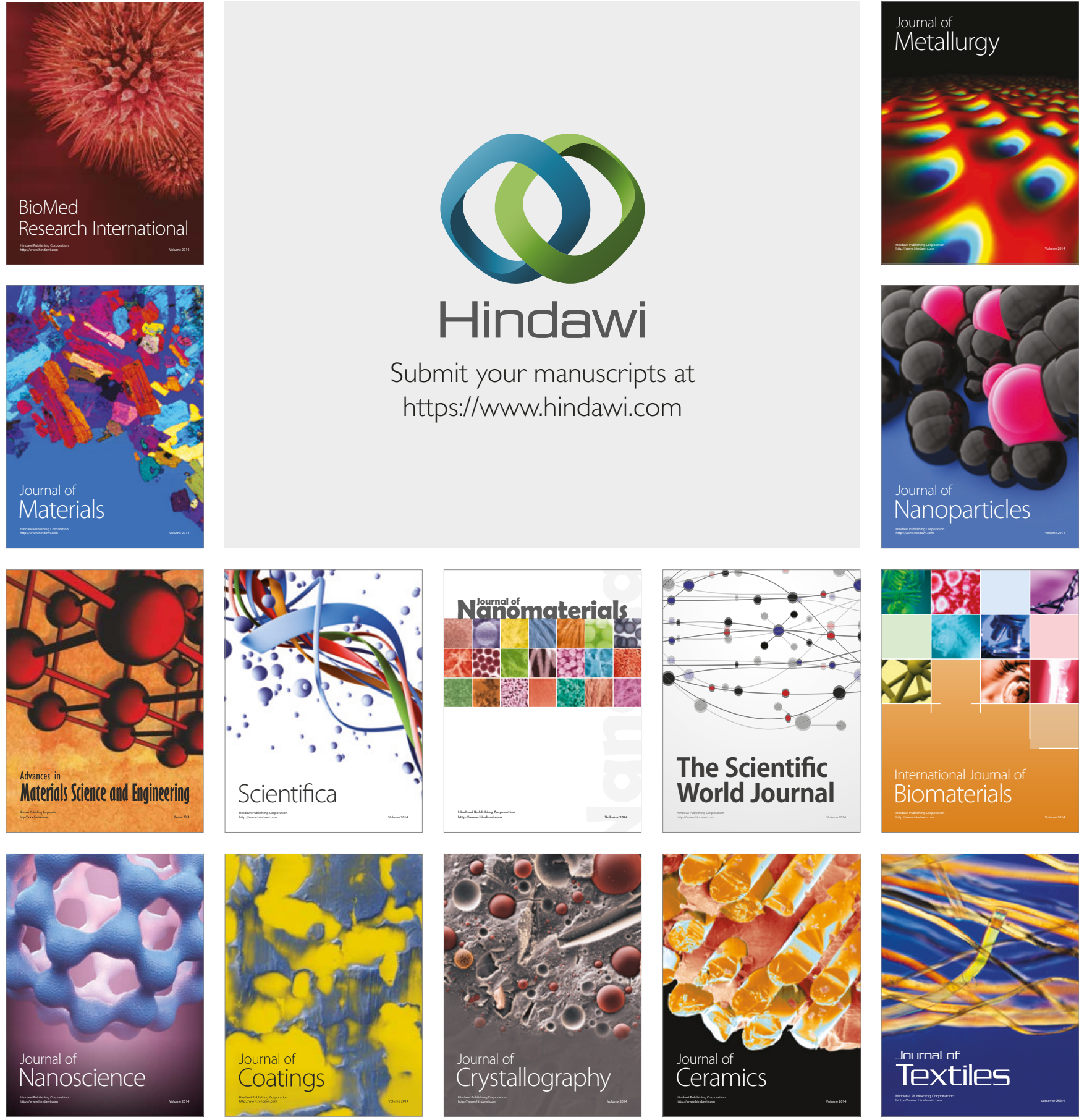

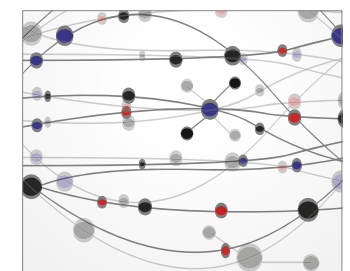

The Scientific World Journal
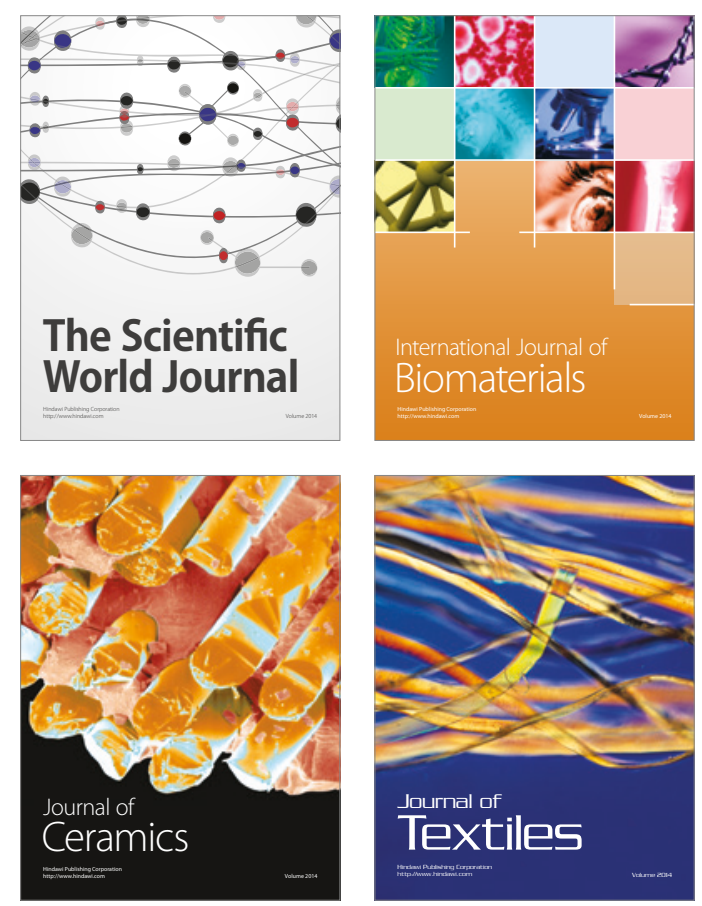